\title{
Joining of Soda Lime Silicate Glass TO TI6AL4V Alloy in Air by Controlled Heat Treatments
}

\begin{abstract}
M. B. TELLI*
Kocaeli University, Metallurgical and Materials Engineering Department, 41380 Izmit/Kocaeli Turkey

Soda lime silicate glass was joined to Ti6Al4V alloy in air by heat treatment at $800{ }^{\circ} \mathrm{C}$ for 10,20 and 30 min and by subsequent cooling to room temperature with a controlled cooling rate. Stresses, due to thermal expansion mismatch, have developed at glass-metal interface after high temperature joining and cooling down to room temperature. The finite element calculations, performed using ANSYS 14 software, suggested that the glass-metal interface was experiencing rather low maximal and minimal principal stresses due to joining. Highest maximal principal stress level was about $25 \mathrm{MPa}$ and lowest minimal principal stress level was about $-40 \mathrm{MPa}$ for used sandwich sample profiles. Heat treatment duration affected tensile bonding strength and interfacial reaction between the glass and the Ti alloy. Scanning electron microscope analysis of glass-alloy joining interface showed that a secondary $\mathrm{K}$, Ca, Ti rich sodium silicate phase was forming in glass, starting at glass alloy interface and that it was growing with the increase in heat treatment duration. Low joining stress levels at the glass-alloy interface for used sandwich sample profile and good bonding between the soda lime silicate glass and Ti6Al4V alloy resulted in creation of successful soda lime silicate glass-Ti6Al4V joints.
\end{abstract}

DOI: 10.12693 /APhysPolA.127.972

PACS: $81.20 . \mathrm{Vj}$

\section{Introduction}

Soda lime silicate glass is one of the economically available glasses which is used often for outdoor applications such as windows [1]. Ti6Al4V alloy is one of the light weight alloys and it is used in some of applications requiring good corrosion resistance, such as biomedical dental applications [2]. Glass-metal joining is needed for wide variety of applications, but it is especially important for heat collecting units, used in parabolic sunlight collector systems [3]. To lower the heat losses, a glass tube sealing of the alloy tube, carrying heated fluid is required. To achieve this, a good glass-metal alloy joining method is necessary. Borosilicate glass-Kovar alloy (having composition of $54 \mathrm{wt} . \% \mathrm{Fe}-29 \mathrm{wt} . \% \mathrm{Ni}-17 \mathrm{wt} . \% \mathrm{Co}$ ) joining is generally used in these applications, due to their closely matched thermal expansion coefficients and good bonding [4]. If soda lime silicate glass-Ti6Al4V alloy joints could be successfully made, they can find uses in such heat collecting tube applications as well. In literature, there are some earlier studies on joining of $\mathrm{SiO}_{2}$ glass to Ti6Al4V alloys, based on vacuum brazing techniques, employing $\mathrm{AgTiCu}$ and $\mathrm{AgTi} / \mathrm{Ni}$ layers [5, 6]. However, there are not many earlier studies aiming for joining of soda lime silicate glass to Ti6Al4V alloy. This study provides (i) a heat treatment procedure for successful joining of soda lime silicate glass-Ti6Al4V alloy in air, (ii) calculations employing finite element method, of maximal and minimal principal stresses at joining interface, due to thermal expansion coefficient mismatch, (iii) results

*e-mail: Mustafa.telli@kocaeli.edu.tr of tensile bonding strength measurement of glass-metal sandwich structure sample profiles, as a function of heat treatment duration, and (iv) investigation of the glassTi6Al4V joining interface by the scanning electron microscope analysis.

\section{Experimental procedure}

Soda lime silicate glass having chemical composition of 69 wt. $\% \mathrm{SiO}_{2}, 1$ wt. $\% \mathrm{~B}_{2} \mathrm{O}_{3}, 3$ wt. $\% \mathrm{~K}_{2} \mathrm{O}, 4$ wt. $\% \mathrm{Al}_{2} \mathrm{O}_{3}$, 13 wt. $\% \mathrm{Na}_{2} \mathrm{O}, 2$ wt.\% $\mathrm{BaO}, 5$ wt. $\% \mathrm{CaO}$ and 3 wt $\%$ $\mathrm{MgO}$ (Schott Ar glass) and Ti6Al4V alloy, having chemical composition of 5.9 wt.\% Al, 4 wt.\% V, 90.1 wt.\% Ti (fulfilling ASTM F136 specification) in its annealed form, were used in the experiments. Samples of required sizes were slowly cut from supplied rods using a diamond saw. The cut pieces were then grinded employing metallographic grinder with a 1000 grade $\mathrm{SiC}$ grinding paper to remove any cutting marks. Two sets of joining samples were prepared: Ti6Al4V (having $12 \mathrm{~mm}$ diameter and $22 \mathrm{~mm}$ height) - soda lime silicate glass (having $10 \mathrm{~mm}$ diameter and $2 \mathrm{~mm}$ height) - Ti6Al4V (having $12 \mathrm{~mm}$ diameter and $21 \mathrm{~mm}$ height), for tensile bonding strength measurements and soda lime silicate glass (having $10 \mathrm{~mm}$ diameter, $2 \mathrm{~mm}$ height) - Ti6Al4V (having $12 \mathrm{~mm}$ diameter, $3 \mathrm{~mm}$ height) for controlling interfacial reactions. Samples were joined by inserting them directly into the furnace preheated at $800{ }^{\circ} \mathrm{C}$ and keeping for the duration of heat treatment of 10,20 and $30 \mathrm{~min}$ in air. The joined samples were then cooled down to $550{ }^{\circ} \mathrm{C}$ during $20 \mathrm{~min}$, and kept for $20 \mathrm{~min}$ at $550{ }^{\circ} \mathrm{C}$ for thermal annealing of glass, to remove any prior developed stress. The joined sample was cooled down from $550{ }^{\circ} \mathrm{C}$ to room temperature slowly, during 4 hrs.

Calculations of the maximal and minimal principal stresses for the used sandwich sample profile were done 
Material properties used in calculations of

TABLE I joining stress with ANSYS 14 software.

\begin{tabular}{c|c|c}
\hline \hline Material property & $\begin{array}{c}\text { Soda lime } \\
\text { silicate glass }\end{array}$ & $\begin{array}{c}\text { Ti6Al4V } \\
\text { alloy }\end{array}$ \\
\hline Therm. expansion coef. & $9.1 \times 10^{-6}[7]$ & $9.7 \times 10^{-6}[8]$ \\
Young's modulus $(E)[\mathrm{Pa}]$ & $7.3 \times 10^{10}[7]$ & $1.14 \times 10^{11}[8]$ \\
Poisson ratio $(\nu)$ & $0.22[7]$ & $0.33[8]$
\end{tabular}

employing ANSYS 14 finite element method software. Table I provides details of the material properties used in the models. Calculations were done assuming that joining stresses were resulted due to cooling down of the bonded glass-alloy joints from the thermal stress relieving annealing step at $550{ }^{\circ} \mathrm{C}$ to room temperature.

Tensile bonding strength measurements of Ti6Al4V alloy - soda lime silicate glass - Ti6Al4V alloy sandwich sample profiles were done by attaching joined samples to Instron Satec Tm Series model tensile tester and applying tensile loading to produce $0.1 \mathrm{~mm} / \mathrm{min}$ extension rate. Maximal tensile stress levels leading to rupture of bonded samples are reported.

Cross section samples of the soda lime silicate glassTi6Al4V alloy, disc on disc samples, were prepared by first placing the joined samples into a polymer based mold, setting at room temperature, then by slowly cutting the molded sample using a diamond saw, to reveal interface between glass and alloy, and finally by grinding the cross sectioned profile by employing the metallographic grinder with a 1000 grade $\mathrm{SiC}$ grinding paper, to reveal joined interface more clearly. Cross sections of the samples were slightly covered by sputtering of $\mathrm{Au}$ to prevent any charging effects prior to scanning electron microscope investigation. Interfacial reactions between the glass and the alloy and the chemical compositions of reaction products were analyzed employing JEOL 6060 model scanning electron microscope with energy dispersive spectrometer with $20 \mathrm{kV}$ acceleration voltage setting.

\section{Results and discussion}

Figure 1 shows the Ti6Al4V - soda lime silicate glass Ti6Al4V sandwich and Ti6Al4V - soda lime silicate glass disc on disc samples, joined at $800{ }^{\circ} \mathrm{C}$ in air for 10,20 and $30 \mathrm{~min}$. All of the samples were successfully joined and there were no sign of macro cracking in the joined glass layers.

Figure 2 shows maximal and minimal principal stress levels calculated for Ti6Al4V - soda lime silicate glass Ti6A14V sandwich sample profiles using ANSYS 14 software. Ti6 Al4V side of the glass-alloy joining interface had the highest maximal stress levels of about $25 \mathrm{MPa}$. The joined glass had a slightly lower maximal principle stress levels of $20 \mathrm{MPa}$ in its outer circumference. The minimal principle stress levels were slightly bigger for the soda lime silicate glass, of about $-40 \mathrm{MPa}$ at the circumference close to the joining interface. The Ti6Al4V alloy had lower minimal principal stress levels

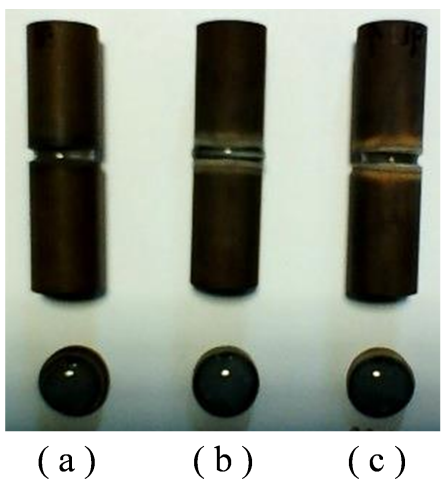

Fig. 1. Ti6Al4V - soda lime silicate glass - Ti6Al4V sandwich samples and soda lime silicate glass disc-ondisc samples, joined at $800{ }^{\circ} \mathrm{C}$ in air, for heat treatment durations of (a) 10, (b) 20 and (c) 30 minutes.

of about $-10 \mathrm{MPa}$ close to joining interface. Calculation results suggest that both soda lime silicate glass and Ti6Al4V had relatively low maximal and minimal principle stress levels after the high temperature joining and the cooling down to room temperature.

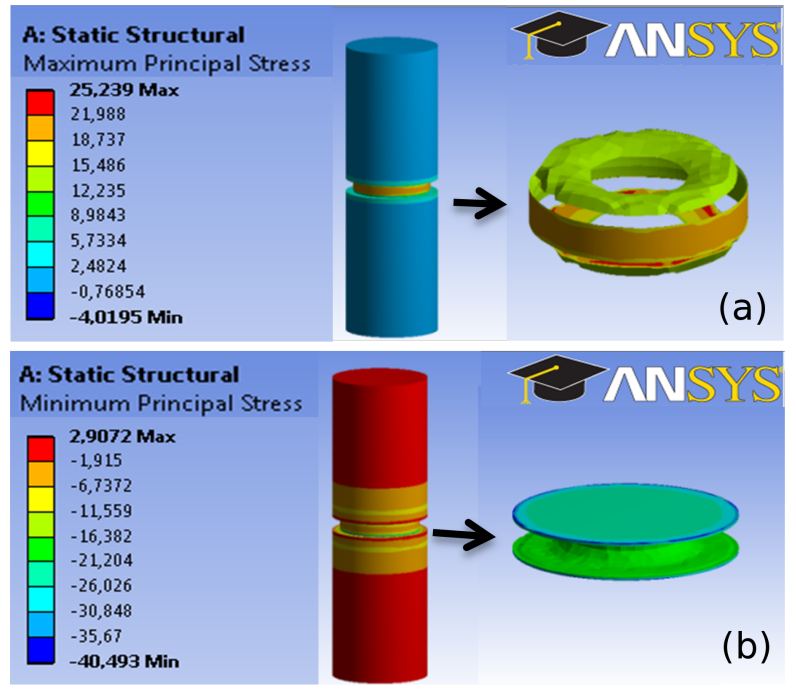

Fig. 2. Results of finite element method calculation of maximal and minimal principal stress levels for Ti6Al4V - soda lime silicate glass - Ti6Al4V sandwich sample profiles. (a) Maximal principal stress levels for whole sample and regions having stress levels higher than $15 \mathrm{MPa}$. (b) Minimal principal stress levels for whole sample and regions having stress levels lower than $20 \mathrm{MPa}$.

Table II shows tensile bonding strength observed for sandwich sample profiles as a function of heat treatment duration at $800{ }^{\circ} \mathrm{C}$ in air. Tensile bonding strength was $19 \mathrm{MPa}$ for sample heat treated for $10 \mathrm{~min}$ and has increased slightly to a level of $27 \mathrm{MPa}$ for sample heat treated for $20 \mathrm{~min}$ and remained at a similar level of $28 \mathrm{MPa}$ for $30 \mathrm{~min}$ heat treatment. Increase in heat treatment duration affected both the fracture modes and the bonding strength of the joined samples. While the 
sample heat treated for 10 min had fractured mostly on the Ti6Al4V - soda lime silicate glass bonding interface, the sample heat treated for $20 \mathrm{~min}$ had fractured within glass layer and the sample heat treated for 30 min had fractured in a complex manner, having regions within both the glass and Ti6Al4V interface. A slight increase in bonding strength with the duration of heat treatment suggested that some interfacial reaction was needed for better bonding between soda lime silicate glass and Ti6Al4V alloy.

\section{TABLE II}

Tensile bonding strengths of samples heat treated at $800{ }^{\circ} \mathrm{C}$.

\begin{tabular}{c|c}
\hline \hline $\begin{array}{c}\text { Treatment } \\
\text { time }[\mathrm{min}]\end{array}$ & $\begin{array}{c}\text { Tensile bonding } \\
\text { strength [MPa] }\end{array}$ \\
\hline 10 & 19 \\
20 & 27 \\
30 & 28
\end{tabular}

Figures 3 and 4 show scanning electron microscope images and energy dispersive spectroscopic analysis (EDS) of sample heat treated for $10 \mathrm{~min}$ at $800{ }^{\circ} \mathrm{C}$. Low magnification secondary electron SEM image $(100 \times)$ suggested that soda lime silicate glass bonded to Ti6Al4V alloy without any micro cracking at the glass-alloy interface. Higher magnification $(1500 \times)$ revealed that a secondary phase was forming in glass region starting from the Ti6Al4V - glass interface. EDS spot analysis taken from interior of glass (spot 1) and the new forming phase (spot 2) suggested that the secondary phase was richer in $\mathrm{K}$, Ca and Ti content compared to used soda lime silicate glass.

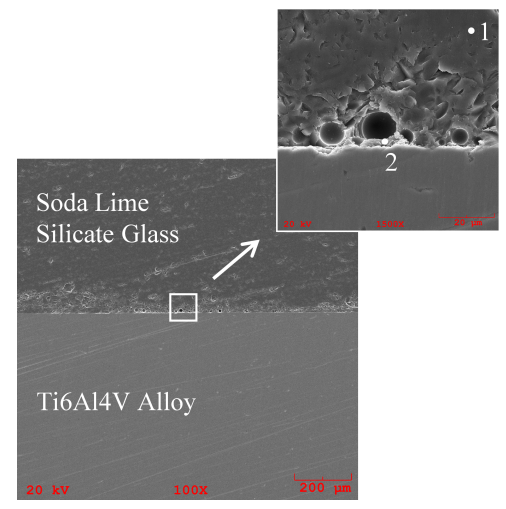

Fig. 3. Scanning electron microscope images of soda lime silicate glass - Ti6Al4V alloy junction sample, heat treated for $10 \mathrm{~min}$ at $800{ }^{\circ} \mathrm{C} .100 \times$ and $1500 \times$ magnified images were taken using secondary electron mode at $20 \mathrm{kV}$ acceleration voltage. $1500 \times$ magnification image also shows spot positions of EDS analysis.

Figure 5 and 6 show scanning electron microscope images of $20 \mathrm{~min}$ and $30 \mathrm{~min}$ heat treated samples at $800{ }^{\circ} \mathrm{C}$. Increase in heat treatment duration lead to more interfacial reactions and further growth of secondary phase. Spot EDS analysis of 30 min heat treated sample (Fig. 7) suggested that chemical composition of secondary phase remained richer in $\mathrm{K}, \mathrm{Ca}$ and $\mathrm{Ti}$ content during its growth.

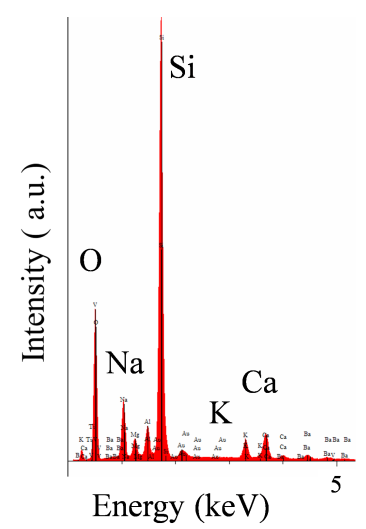

( a )

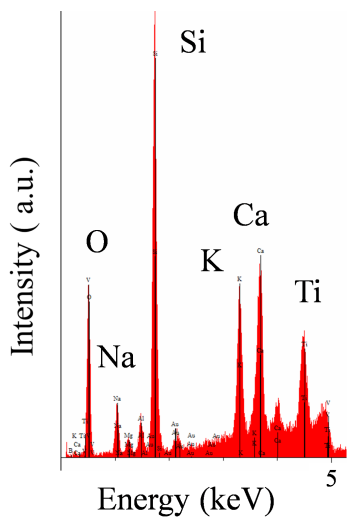

( b )
Fig. 4. Energy dispersive spectroscopic analysis of sample heat treated for $10 \mathrm{~min}$ at $800{ }^{\circ} \mathrm{C}$ : (a) interior of soda lime silicate glass (spot position 1, shown in figure 3 ), (b) secondary phase, formed at glass-alloy interface (spot position 2 , shown in figure 3 ).

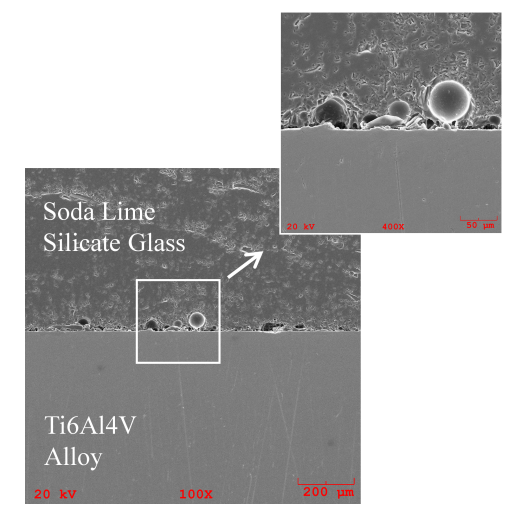

Fig. 5. Scanning electron microscope images of soda lime silicate glass - Ti6Al4V alloy junction sample heat treated for $20 \mathrm{~min}$ at $800{ }^{\circ} \mathrm{C} .100 \times$ and $400 \times$ magnified images were taken using secondary electron mode at $20 \mathrm{kV}$ acceleration voltage.

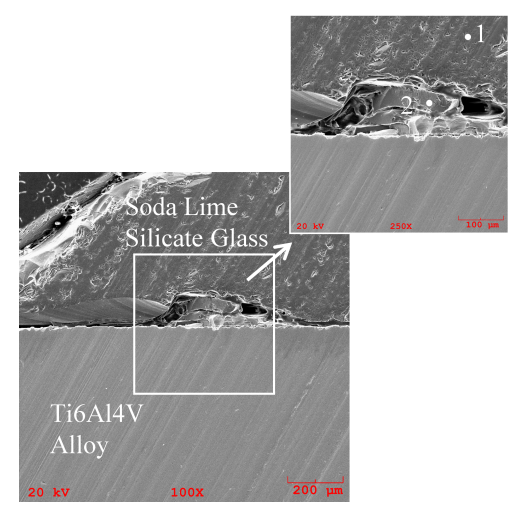

Fig. 6. Scanning electron microscope images of soda lime silicate glass - Ti6 Al4V alloy junction sample heat treated for $30 \mathrm{~min}$ at $800{ }^{\circ} \mathrm{C} .100 \times$ and $250 \times$ magnified images were taken using secondary electron mode at $20 \mathrm{kV}$ acceleration voltage. $250 \times$ magnification image also shows spot positions of EDS analysis. 


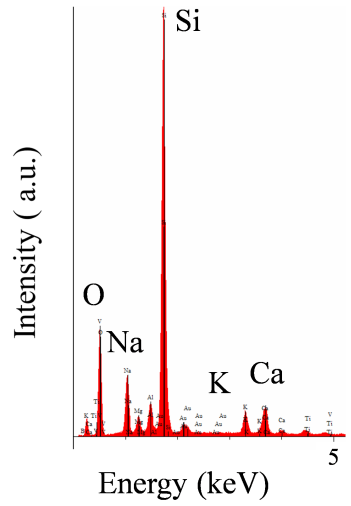

( a )

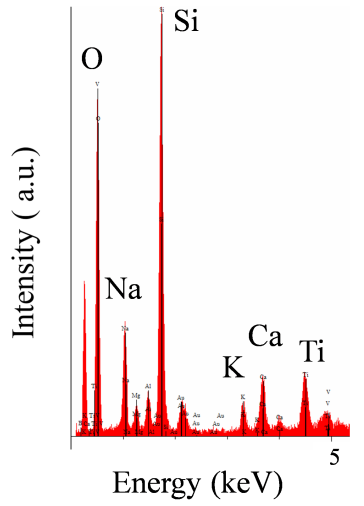

( b )
Fig. 7. Energy dispersive spectroscopic analysis of sample heat treated for $30 \mathrm{~min}$ at $800^{\circ} \mathrm{C}$ : (a) interior of soda lime silicate glass (spot position 1, shown in figure 6), (b)secondary phase formed at glass-alloy interface (spot position 2, shown in figure 6).

Formation and growth of the $\mathrm{K}, \mathrm{Ca}$, Ti rich sodium silicate-based secondary phase at soda lime silicate glass - Ti6Al4V interface thought to be related to initial oxide layer formation of Ti6Al4V alloy in air at $800{ }^{\circ} \mathrm{C}$, Ti diffusion into the glass from Ti6Al4V alloy, nucleation of secondary phase from initially formed oxide layer of Ti6Al4V alloy and its growth within the glass with the increase in heat treatment duration. More studies are needed to analyze all these effects clearly in more detail but not scope of this study.

\section{Conclusions}

Soda lime silicate glass was joined successfully to Ti6Al4V alloy by heat treating at $800{ }^{\circ} \mathrm{C}$ in air for 10, 20 and 30 minutes. Having low joining stresses and good interfacial bonding were found to be producing successful joints. Based on finite element method calculations, joined parts were subjected to low maximal and minimal principle stress levels. For the used sandwich sample profile, highest maximal principal stress of about $25 \mathrm{MPa}$ was calculated for
Ti6Al4V side of the glass - alloy joining interface and lowest minimal principal stress about $-40 \mathrm{MPa}$ was calculated for the soda lime silicate glass at its circumference, close to joining interface. Tensile bonding strength of glass - Ti alloy joint was dependent on heat treatment duration and increased from $20 \mathrm{MPa}$ for sample heat treated for $10 \mathrm{~min}$, to $30 \mathrm{MPa}$ for samples heat treated for 20 and $30 \mathrm{~min}$, suggesting some interfacial reaction was needed to improve bonding strength. Scanning electron microscope investigation showed that a secondary phase rich in $\mathrm{K}$, Ca and $\mathrm{Ti}$ content, compared to the content of the used glass, was forming at glass - Ti alloy interface for sample heat treated for $10 \mathrm{~min}$ and growing further with the increase in heat treatment duration to 20 and 30 min. Low joining stress levels due to similar thermal expansion coefficients and good interfacial bonding was concluded to be causing successful soda lime silicate glass - Ti6Al4V alloy joints in air.

\section{Acknowledgments}

This study was financially supported by scientific research project 2011-70 of Kocaeli University, Turkey.

\section{References}

[1] J.E. Shelby, Introduction to Glass Science and Technology: $2^{\text {nd }}$ Edition, The Royal Society of Chemistry, Cambridge UK 2005.

[2] C. Lyens, M. Peters, Titanium and Titanium Alloys: Fundamentals and Applications, WILEY-VCH Verlag, Weinheim Germany 2003.

[3] D. Lei, Z. Wang, J. Li, Mater. Design 31, 1813 (2010).

[4] C. Chanmuang, M. Naksata, H. Jain, C.E. Lyman, Mater. Sci. Eng. A 474, 218 (2008).

[5] H.B. Liu, L.X. Zhang, L.Z. Wu, D. Liu, J.C. Feng, Mater. Sci. Eng. A 498, 321 (2008).

[6] J.C. Feng, D. Liu, L.X. Zhang, X.C. Lin, P. He, Mater. Sci. Eng. A 527, 1522 (2010).

[7] "Schott tubing brochure for ar-glass", http://www. schott.com.

[8] "Ti6Al4V grade 5 alloy annealed bar properties", http://www. matweb. com. 